\title{
The direct observational method and possibilities for Neotropical Carnivores: an invitation for the rescue of a classical method spread over the Primatology
}

Primates and carnivores belong to phylogenetically distant mammal orders (Murphy et al. 2001). Overall, carnivores have developed some very particular and conservative characteristics during the process of evolution, whereas primates have held to a more plesiomorphic bauplan that emphasizes adaptability over adaptation (SIMPSON 1980). Such differences in the history of each group have resulted in remarkable anatomical, ecological, and behavioral differences.

The most commonly studied interactions between primates and carnivores are between predator and prey (e.g., Treves 1999, ZuberbüHLer \& Jenny 2002). While some interactions are of a competitive nature (e.g., Rose et al. 2003, Treves \& PALmQvist 2007), mutual interactions are rare (e.g., SCHLEIDT \& SHALTER 2003, Haugaasen \& Peres 2008). In hunting interactions, primates are usually the prey, though in some cases both humans (e.g., JoRgENSON \& REDFORD 1993) and non-human primates (e.g., Rose et al. 2003) predate upon carnivores. Hunting by and competition from carnivores have significantly contributed to molding some characteristics of primate biology, including our hominid ancestors (Treves 1999, Treves \& Palmovist 2007). Currently, the conflict between modern humans and carnivores that attack domestic animals results in strong pressure on predator populations (see Treves \& Karanth 2003, Shivik 2006).

Despite the conflict of interests inherent to their interactions, and also because of the differences in their evolutionary biology, both groups present several similarities from a scientific point of view. Previous studies have compared primates and carnivores, especially with regards to some aspects of their socioecology (e.g., Wrangham et al. 1993, KaYs \& GitTleman 2001, Sмiтн et al. 2008). Some investigators have treated infanticidal behavior (e.g., Parmigiani \& Vom SAal 1994), hunting behavior (e.g., Boesch \& Boesch 1989), and even the convergent morphology between the two groups (e.g., Plavcan \& Ruff 2008). In a high proportion of such investigations, especially on behavior, studies with primates are used as a model and basis for comparison. The conceptual and theoretical background to understand this line of research in the carnivores stems from such work. However, irrespective of the taxonomic group, studies of behavior and especially socioecology strongly depend upon direct observation of the animals in the wild. In this case, common objectives require methods in common.

For primates, the direct-observation study method, which has been used for a broad range of organisms since the natural world began to be scientifically studied, is widespread. For carnivores, direct observation has been more often employed in the Palaeotropic and Nearctic regions, and studies using direct observation in the Neotropical region are very rare, in spite of the existing possibilities. Indeed, it is exactly in this region that the behavior, socioecology, and certain other aspects of the biology of carnivores are poorly understood. The aim of the present study is therefore to address this gap in the Neotropics.

The advantage of primates and the problem of carnivores in the Neotropics

It has been possible to study the ecology and behavior of primates by following and observing them directly in several locations in South and Central America, because they are conspicuous, and also because of their daily habits and the relative ease with which they become habituated to the observer (the same is true for the Old World primates). Consequently, many scientific questions about this order could be answered. The Neotropical primates constitute a valuable heritage of biodiversity, especially in conservation and biomedical investigations (CoImbra-FilHo 2004). They are good objects of study to understand forest environments, and are essential components of conservation strategies (RyLANDs et al. 1997, SECHREST et al. 2002). Many Neotropical primates were the main elements in many successful and internationally recognized conservation programs. In Brazil, the history of conservation is thoroughly intertwined with the history of primatology (CoImbraFilho 2004, MitTermeier et al. 2005).

The predominant forest physiognomy in the Neotropical Region and the nocturnal and cathemeral habits of many animals, including many carnivores, pose difficulties to animal direct observation in the wild for long periods of time. Compared with the primates, the Neotropical carnivores are neither well studied nor understood (see Crawshaw 2006, Oliveira 2006). Despite the possibilities for data collection through direct observation, some of their habits (feeding, use of space, and activity patterns) and population numbers have been mostly investigated using indirect methods, such as feces analysis, footprint identification, radio telemetry, and photographic trigger systems (camera traps). The lack of behavioral and socio-ecological studies, which are only possible through direct observation, creates an obstacle to a full understanding of the biology of these animals. This gap creates problems when trying to devise conservation actions in situ or ex situ, especially for sensitive animals at the top of the food chain (for the importance of behavioral studies in conservation biology, see KNIGHT 2001, ANGELONI et al. 2008).

Much basic but essential information about the great majority of Neotropical carnivores still needs to be obtained, 
and these animals must be observed in the wild if we want to gain a better understanding of their biology. Because of the lack of basic information, many species are not included in lists of threatened fauna or are simply assigned to categories of animals about which there is insufficient knowledge [e.g., Atelocynus microtis (Sclatter, 1883); Nasuella olivacea (Gray, 1865); Bassaricyon spp. (Chiarello et al. 2008, IUCN 2009)]. For this reason, the present study aims to encourage wider dissemination of a classical method that is often used in studies with free-ranging primates, but is insufficiently used by Neotropical carnivore researchers. Here we propose the increased use of methods (habituation, following, and direct observation) that have been applied since the primordial human state, to understand some carnivores more profoundly. We are not advocating against the indirect methods that are currently used in research on carnivores, which have been widely used and have provided valuable information on the biology (see EISENBERg et al. 1970) and behavior of rare and cryptic animals (e.g., PIERCE et al. 2000). Rather, we are merely pointing out to the possibility of using a low-cost and effective method to improve the collection and refine the quality of data, especially with regards to behavior, a crucial and under-represented area of study when we take the present state of knowledge on Neotropical carnivores (see MacNulty et al. 2007) into account. This essay does not propose a novel method, although it encourages field biologists to consider the possibility of observing animals, as much as possible, by using a common method in appropriate environments. For instance, a field biologist might consider the possibility of directly observing maned wolves, Chrysocyon brachyurus (Illiger, 1815), in the pampas and the Brazilian cerrado, rather than using only radio-telemetry triangulation. To make it possible and in order to maintain the quality of the data collected and to avoid bias, a first and essential step must be carefully planned and applied by the researcher: the habituation process.

\section{Direct observation and the process of habituation}

Concerning free-ranging animals (including primates, many carnivores, and other vertebrates), ecology and behavior studies are successfully accomplished by following and observing them directly. Differently from indirect records, the method of direct observation in the wild allows for everything that can be observed or heard to be recorded in real time. Therefore, automatic video recording will not be considered here as a directobservation method. Despite its efficiency for the analysis of some kinds of behavior (see ScHeibe et al. 2008), this method does not require that the animal be followed by the observer through its habitat. For this reason, the results may be biased and a reductionist interpretation may arise when samples are stationary at one or a few microhabitats. However, for certain very cryptic and shy animals such as some forest felids, the use of these and other similar methods of observation (e.g., to wait in blinds or to use guided cameras) may be more practical.

Because of the presence of an observer, the results gained by direct observation may be tendentious. In order to eliminate or greatly reduce bias before one starts to collect data, the human observer must plan a way to interfere as little as possible with the animals' behavior. Some effort with the habituation process is usually necessary. Briefly, the process of habituation consists of repeated encounters between the object of study (animals) and humans, which will cause the animals to become less frightened and curious about the humans, and eventually will cause the animal to ignore the observer for long periods of time (Williamson \& Feistner 2003). It is known that the amount of time required for animals to become accustomed to an observer varies according to the species' biology, the environment (e.g., the presence or absence of predators or human hunters), and investment: from nearly immediate results in the habituation of Strepsirhini in Madagascar, to a decade or more in the habituation of great apes (Williamson \& Feistner 2003, Doran-Sheehy et al. 2007). However, some problems may arise. Although it is expected that by the end of the process the observer will be completely accepted by the animal, the observer will not always be a neutral element (see JACK et al. 2008). At sites where hunting pressure is strong, habituation will hardly ever reach an ideal level (Williamson \& Feistner 2003). There are also risks of injury and transmission of diseases for both observer and subject (WOODFORD et al. 2002, Williamson \& Feistner 2003, Doran-Sheehy et al. 2007).

Despite the effort required and the obstacles encountered, the efficiency of the process of habituation to the observer, with minimum interference with its object of study, is certain. The method makes it possible to become familiar with individuals, and to collect behavioral and other kinds of information of a better quality (Williamson \& Feistner 2003). It is the experience in the field that allows the observer to define and work at the best distance between himself and his object of study. The researcher in the field, in his first interactions with the animals, will decide how to behave towards the different activities performed by the animal, optimizing the data collection. Most studies of free-ranging primates have been carried out in this manner. A large amount of work with carnivores, especially in the Old World and in the Nearctic Region, has also been conducted using the habituation method. Unfortunately, in the Neotropical Region, this method is not widely used. Except for some examples where investigators attempted to make observations in a systematic way (e.g., MonTGOMERY \& Lubin 1978, Brady 1979, MacDonald \& Courtney 1996, Gompper 1996, Bank \& Franklin 1998, Beisiegel 2001, Kays \& Gittleman 2001, CourTney et al. 2006), nearly all that is known about Neotropical carnivores has come from indirect records. Before discussing the applications and the potential of the direct-observation method to the study of Neotropical carnivores, we will briefly summarize some of its important applications and results, which have improved our knowledge of carnivores in the Nearctic Region, and especially in the Old World.

\section{Lessons from the Old World}

The study of carnivores in the Old World and also in the Nearctic Region by following and direct observation is wide- 
spread. This method enables people to observe the behavior of large predators from a remote location on television. In some species, direct observation of large carnivores has been a superior and more accurate method for the study of diet (MilLs 1992) than the analysis of their feces. In several studies in Africa, North America, and Asia, the observers succeeded in habituating carnivores to their presence and were then able to continue observing them for hundreds or sometimes thousands of hours in the field. By doing so, many questions about the social structure, development and learning process, food sharing, strategies of foraging and hunting, courtship behavior, vigilance, cooperation, reciprocity, territorial behavior, and construction of ethograms, among other issues, were clarified. Elucidating the behavior of these carnivores in different environmental physiognomies was also an important step in developing translocation schemes for conservation purposes (HAYWARD et al. 2006).

Important examples of information obtained by direct observation are available from several regions in the world. The detailed description of the ethogram of wolves (Canis lupus Linnaeus, 1758) and their complex hunting behavior in the wild revealed crucial information for discussions about their feeding ecology and foraging strategies (MacNulty et al. 2007). In Africa, the pattern of daily activity, hunting strategies, and interaction of hyenas, e.g., Crocuta crocuta (Erxleben, 1777), and lions, Panthera leo (Linnaeus, 1758), were studied through the direct-observation method (e.g., Funston et al. 1998, Kolowski et al. 2007, Sмiтн et al. 2008). The hunting habits of cheetahs [Acinonyx jubatus (Schreber, 1775)] were also studied intensively in the wild, making it possible to accurately determine their preferences for prey, conditions for hunting success, risk of injury, and the role of competition with other large carnivores in their survivorship (DURANT 2000, HaYward et al. 2006). The observation of African wild dogs, Lycaon pictus (Temminck, 1820), led to a better understanding of how the presence of hyenas, (their competitors) affects their strategies and successful hunting and consequently the maintenance of their populations (CARBONE et al. 2005). This knowledge has afforded a better comprehension of the costs and processes of evolution that molded some parameters in the community of African predators (Durant 2000, Hayward et al. 2006).

Studies through direct observation were also important for the understanding of the reproductive success of carnivores under social restrictions. Studies involving many hours of observation on the social system of hyenas, lions, wild dogs, and meerkats, Suricata suricatta (Schreber, 1776), have established that there are remarkable differences in reproductive success according to the level of hierarchy, dominance, and the system within and between groups (Creel et al. 1997, Fuston et al. 1998, Hofer \& EAST 2003, Russel et al. 2003). Direct-observation studies have shown that several species of canids and civets have cooperative offspring care performed by non-reproductive individuals, which can increase the reproductive success of the group (EMLEM 1991; AsA \& VALDESPINO 1998) - a phenomenon also widespread among
Neotropical primates of Callitrichinae (Goldizen 1990). Knowledge of infanticidal behavior has advanced considerably through observation of lions and comparisons with other vertebrates, including several species of primates (see PARMIGIANI \& VOM SAAL 1994). These and other studies have great applicability and importance for better comprehension of the structure, interaction, performance, and success of the populations and communities of Neotropical carnivores.

\section{Applications and a promising outlook in the Neotropical Region}

As previously mentioned, few studies performed by direct observation of Neotropical carnivores exist, which has left many gaps in the knowledge of this group. This may result not only from the difficulties imposed by the species and environments, but also because some scientists simply do not think of it, or have preconceptions about the validity of the method of following and direct observation.

Some records exist from the opportunistic direct observation of predation events of the maned wolf on deer (Bestelmeyer \& Westbrook 1998), bush dogs, Speothos venaticus Lund, 1842, on tapirs and agoutis (Deutsch 1983, Wallace et al. 2002), and the puma, Puma concolor (Linnaeus, 1771), and Geoffroy's cat, Leopardus geoffroyi d'Orbigny \& Gervais, 1844, on rodents (BRANCH 1995). Even occasional direct observation has excluded doubtful interpretations and has revealed some hunting strategies and also social hunting in some species that had been considered solitary (WASER et al. 1994, Gehrt \& Fritzell 1998). These and other examples which will be discussed below show that what has been done for a long time, especially in the Old World, can find applications in the Neotropical Region.

\section{Procyonidae in forests}

The lack of studies on the biology of the most common carnivores in Neotropical environments was discussed during the First Workshop on Neotropical Carnivores (2006), held in the South American Congress of Mastozoology, city of Gramado, Rio Grande do Sul, southern Brazil. As mentioned there, ordinary, abundant, generally ruderal, or even charismatic animals such as the semi-arboreal coatis are little studied. While most studies have employed the aforementioned indirect methods, a few successful instances of following and direct observation (e.g., BeISIEgel 2001, GOMPPER 1996) have been reported. This may appear to be a very few studies, especially on animals with habits similar to the semi-terrestrial capuchin monkey, Cebus Erxleben, 1777. Consistent with our field experience, coatis, like the primates, can become accustomed to the presence of humans. In the words of BeIsiegel (2001): "The high frequency of absence of escape in spite of the human observer and the possibility of following a group for long periods suggest the viability of habituating the animals to observational study". Therefore, coatis could be followed and observed directly, allowing the collection of more-refined behavioral data, closing gaps in the knowledge of their natural history. The study 
of GOMPPER (1996) is also a rare example in which direct observation of white-nosed coatis, Nasua narica (Linnaeus, 1766), in Panama resulted in a comprehension of the socioecology of this group of carnivores. We note that in end of his study, the author compared the social system of coatis with the previously known fission/fusion system in primates such as the spider monkey, Ateles E. Geoffroy, 1806).

As previously mentioned, the cathemeral or nocturnal habits of many carnivores can impose obstacles to the method of following and direct observation. However, although the method may be difficult, it may not necessarily be impossible. Monitoring studies of nocturnal Strepsirhini in Madagascar and the nocturnal owl monkey, Aotus Illiger, 1811, in the Neotropical Region have shown that if the subject and the environment allow, and the researcher is creative and perseverant, these animals can be followed under very low-light conditions. Considering only the Neotropical groups, the studies of FerNANDÉzDUQUe \& ERKERT (2006) have shown that the cathemerality of the owl monkey in Argentina can aid researchers in following them. In Mexico, Estrada \& Coates-Estrada (1985) analyzed the behavior of Aotus at night using night-vision equipment. GARCIA \& BRAzA (1987) also studied the behavior of these animals during the night, lighted only by moonlight. Therefore the nocturnal primates can also be studied through direct observation. But what does this have to do with the Neotropical carnivores?

The kinkajou, Potos flavus (Schreber, 1774), a rarely studied Neotropical procyonid, is similar in certain respects to some lemurs and owl monkeys (Ford \& Hoffman 1988). For this reason, little effort is required to realize the possibility of the application of the direct observation method to study these animals in the wild, although few such studies exist. In an interesting project, KaY \& GitTleman (2001) studied the social system of kinkajous by following them at night, and clarified the social system of these animals by comparing them to primates.

These examples may suggest that our proposal could only apply to carnivores with similar bodies, habits, and environment as primates, but this seems not to be the case.

\section{Other environments, other animals, other difficulties to overcome}

In aquatic environments, little-studied carnivores such as Neotropical otters, Lontra Gray, 1843, see OliveIRA (2006), and the critically threatened giant otter, Pteronura brasiliensis (Gmelin, 1788), can be amenable to habituation and direct observation (Rosas et al. 2007). In fact, methods for studying the behavior of free-ranging aquatic mammals such as these and others (pinnipeds and cetaceans) usually use direct observation (e.g., BALDI et al. 1996, SIMÕEs-Lopes 2005).

Another aspect that causes difficulty for the study of some Neotropical carnivores and that must be considered is that, in general, the home ranges of carnivores tend to be larger than those of primates. For instance, it can be very difficult to locate, habituate, and follow a solitary, rare and cryptic jaguar through its large home range of approximately $65 \mathrm{~km}^{2}$ (see MAFFeI et al.
2004), what can be interpreted as a good argument against the possible success of direct observation in the study of other Neotropical carnivores. However, this argument falls in the face of studies such as those of BANK \& FRANKLIN (1998), who habituated and followed the other large, cryptic and solitary Neotropical felid, the puma; and Doran-SHeEhy et al. (2007), who studied rare gorillas in their large home ranges. Despite the prevalence of large home ranges in Neotropical carnivores, small home ranges of 1 to $2 \mathrm{~km}^{2}$ have been recorded for smaller carnivores such as the crab-eating fox, Cerdocyon thous (Linnaeus, 1766), and the pampas fox, Lycalopex gymnocercus (Fischer, 1814) (MAFFei et al. 2007). The dimensions of these small ranges are similar to the home ranges of the rare lion tamarin, Leontopithecus Lesson, 1840, between 0.4 and $3.2 \mathrm{~km}^{2}$ (Kierullf et al. 2002), in which it is assumed that it would be virtually impossible to work with these animals without the support of radio-telemetry or a GPS. Since this method is used with these primates to first find them and then to follow them, it could also be considered for these foxes - and also for the maned wolf in the cerrado, zorrilhos Conepatus chinga (Molina, 1782) in open fields, and even for the arboreal margay Leopardus wiedii (Schinz, 1821). This technology could be used to facilitate the encounters of observers and foxes, enabling their habituation and eventually allowing them to be followed and observed directly.

MONTGOMERY \& Lubin (1978) and BRADY (1979) pioneered in demonstrating the possibility of following the crab-eating fox as a method of behavioral investigation, without the support of telemetry. Only later did MacDonald \& Courtney (1996) and COURTNEY et al. (2006) combine the methods of telemetry, following, and direct observation in the study of foxes. Subsequently, new and more-refined results on parental care and the social system of foxes have been reached that were only possible to obtain through direct methods. In the pampas of southern Brazil, experiments on the habituation of free-ranging pampas foxes by one of the authors (RF Moro-Rios \& JE Silva-Pereira, data not published) have been successful. In spite of the difficulties imposed by the primarily nocturnal habit of these foxes, a new range of data about their behavior and ecology could be gathered through the process of habituation and following.

\section{Final considerations and conclusions}

Continuous application of the same methods to the same objects of study without any innovation can keep knowledge of a certain group or subject in a period of stasis. Certain traditions of research have already demonstrated their success and applicability. However, history has shown that success can be temporary. The evil of stagnation can follow systems until new or even forgotten concepts, paradigms, or methods appear (see KuHN 1970, Gould 2002). Knowing when and how to innovate creates a new step or a new scenario and another level of knowledge. However, innovation hardly ever appears out of the blue; on the contrary, in general it is already latent or is applied to other purposes (Nietzsche 1887, Gould 2002). The simple adaptation or exchange of methods between the different traditions 
in the field of mammalogy will bring new insights into presently little-understood animals. Low-cost methods (habituation, following, and direct observation) that were widely applied with excellence throughout the classical period of natural history, especially in primatology, and that would fill some gaps in the biology of Neotropical carnivores, could be resurrected, improving and expanding the knowledge of these animals to another level. Nowadays, the study of the order Carnivora is far from being in stasis, although with the resurrection and adoption of simple methods in its traditions of research, the production of knowledge could be optimized.

Similarly to the researchers who followed wolves in the snows of the Nearctic region, and hyenas, lions, and guepards in the African savannas, scientists could habituate, follow and study carnivores in the open environments of our pampas and cerrados, and even in closed forests. We hope that this essay will stimulate further discussions on studies of mammalian behavior through one of the most traditional methods in all of biology. For this reason, we suggest that researchers on carnivores (and why not the other mammals?) ask themselves an important question: and what if we followed them? If there is the possibility of an affirmative answer, why not use this method? Perhaps our encounters with these animals would change from rare and occasional to common and habitual.

\section{ACKNOWLEDGEMENTS}

We thank CNPq for scholarships to the authors; José E. Silva-Pereira, Diego Bilski, James J. Roper, Fernando C. Passos, and the reviewers who positively criticised different versions of this text; and Kaue C. Abreu, Emydgio L.A. Monteiro-Filho, and Tadeu G. Oliveira, who made encouraging comments. This is the contribution number 1783 from the Departamento de Zoologia, Universidade Federal do Paraná

\section{LITERATURE CITED}

Angeloni, L.; M.A. Schlaepfer; J.J. Lawler \& K.R. Crooks. 2008. A reassessment of the interface between conservation and behaviour. Animal Behaviour 75 (2): 731-737.

Asa, C.S. \& C. Valdespino. 1998. Canid reproductive biology: an integration of proximate mechanisms and ultimate causes. American Zoologist 38: 251-259.

Baldi, R.; C. Campagna; S. Pedraza; B.J. Le Bouf. 1996. Social effects of space availability on the breeding behaviour of elephant seals in Patagonia. Animal Behaviour 51 (4): 717-724.

Bank, M.S. \& W.L. Franklin. 1998. Puma (Puma concolor patagonica) feeding observations and attacks on guanacos (Lama guanicoe). Mammalia 62: 599-605

Beisiegel, B.M. 2001. Notes on the coati Nasua nasua (Carnivora: Procyonidae) in an Atlantic Forest area. Brazilian Journal of Biology 61 (1): 689-692.

Bestelmeyer S.V. \& C. Westbrook. 1998. Maned wolf (Chrysocyon brachyurus) predation on pampas deer (Ozotoceros bezoarticus) in Central Brazil. Mammalia 62 (4): 591-595.

Boesch, C. \& H. Boesch. 1989. Hunting behavior of wild Chimpanzees in the Taï National Park. American Journal of Physical Anthropology 78 (4): 545-573.

Brady, C.A. 1979. Observations on the behavior and ecology of the crab-eating fox (Cerdocyon thous), p. 161-167. In: J.F.EISENBER (Ed.). Vertebrate Ecology in the Northern Neotropics. Washington, Smithsonian Institution Press, 271p.

BrANCH, L. 1995. Observations of predation by pumas and Geoffroy's cats on the plains vizcacha in semi-arid scrub of central Argentina. Mammalia 59 (1): 152-156.

Carbone, C.; L. Frame; G. Frame; J. Malcolm; \& J. Fanshawe. 2005. Feeding success of African wild dogs (Lycaon pictus) in the Serengeti: The effects of group size and kleptoparasitism. Journal of Zoology 266: 153-161.

Chiarello, A.G.; L.M.S. Aguiar; R. Cerqueira; F.R. Melo; F.H.G. Rodrigues \& V.M.F. SiLVA. 2008. Mamíferos, p. 680-880. In: A.B.M.Machado; G.M. Drummond \& A.P. Paglia (Eds). Livro vermelho da fauna ameaçada brasileira. Belo Horizonte, Biodiversitas, 1420p.

Coimbra-Filho, A.F. 2004. Os primórdios da primatologia no Brasil, p. 11-35. In: S.L. Mendes \& A.G. Chiarello (Eds). A Primatologia no Brasil 8. Vitória, Editora da UFES, 340p.

Courtenay, O.; D.W. Macdonald; S. Gillingham; G. Almeida \& R. DiAs. 2006. First observations on South America's largely insectivorous canid: the hoary fox (Pseudalopex vetulus). Journal of Zoology 268 (1): 45-54.

Crawshaw, P.G. 2006. The history of carnivore research in Brazil, p. 15-37. In: R.G. Morato; F.H.G. Rodrigues; E. Eizirik; P.R. Mangini; F.C.C. Azevedo \& J. Marinho-Filho (Eds). Manejo e conservação de carnívoros neotropicais. São Paulo, Ibama, 396p.

Creel, S.; N.M. Creel; M.G.L. Mills \& S.L. Monfort. 1997. Rank and reproduction in cooperatively breeding African wild dogs: behavioral and endocrine correlates. Behavioral Ecology 8: 298-306.

Deutsch, L. 1983. An encounter between bush dog (Speothos venaticus) and paca (Agouti paca). Journal of Mammalogy 64 (3): 532-533.

Doran-Sheehy, D.M.; A.M. Derby; D. Greer \& P. Mongo. 2007. Habituation of Western Gorillas: the process and factors that influence it. American Journal of Primatology 69 (12): 1354-1369.

DURANT, S.M. 2000. Living with the enemy: avoidance of hyenas and lions by cheetahs in the Serengeti. Behavioral Ecology 11 (6): 624-632.

Eisenberg, J.F.; C. Santiapillai \& M. Lockhart. 1970. The study of wildlife populations by indirect methods. The Ceylon Journal of Science, Biology Sciences 8 (2): 53-62.

EMLEM, S.T. 1991. Evolution of cooperative breeding in birds and mammals, p. 301-337. In: J.R. Krebs \& N.B. Davies (Eds). Behavioural ecology. An evolutionary approach. Oxford, Blackwell Scientific Publications, 464p. 
Estrada, A. \& R. Coates-Estrada. 1985. A preliminary study of resource overlap between howling monkeys (Alouatta palliata) and other arboreal mammals in the tropical rain forest of Los Tuxtlas, Mexico. American Journal of Primatology 9 (1): 27-37.

Fernandez-Duque, E. \& H. Erkert. 2006. Cathemerality and lunar periodicity of activity rhythms in owl monkeys of the Argentinian Chaco. Folia Primatologica 77 (1): 123-138.

Ford, L. \& R. Hoffmann. 1988. Potos flavus. Mammalian Species 321 (1): 1-9.

Funston, P.J.; M.G.L. Mills; H.C. Biggs; P.R.K. Richardson. 1998. Hunting by male lions: ecological influences and socioecological implications. Animal Behaviour 56 (6): 1333-1345.

Garcia, J.E. \& F. Braza. 1987. Activity rhythms and use of space of a group of Aotus azarae in Bolivia during the rainy season. Primates 28 (3): 337-342.

Gehrt, S.D. \& E.K. FritzelL. 1998. Resource distribution, female home range dispersion and male spatial interactions: group structure in a solitary carnivore. Animal Behaviour 55 (5): 1211-1227.

Goldizen, A.W. 1990. A comparative perspective on the evolution of tamarin and marmoset social systems. International Journal of Primatology 11 (1): 63-83.

GoMPPER, M.E. 1996. Sociality and asociality in white-nosed coatis (Nasua narica): foraging costs and benefits. Behavioral Ecology 7 (3): 254-263.

Gould, S.J. 2002. The structure of evolutionary theory. Massachusetts, Harvard University Press, 1392p.

Haugaasen, T. \& C. Peres. 2008. Associations between primates and other mammals in a central Amazonian forest landscape. Primates 49 (3): 219-222.

Hayward, M.W.; J.O'Brien; M. Hofmeyr \& G.I.H. Kerley. 2006. Prey preferences of the cheetah Acinonyx jubatus: morphological limitations or the need to capture rapidly consumable prey before kleptoparasites arrive? Journal of Zoology 270: 615-627.

Hofer, H. \& M. EAST. 2003. Behavioral processes and costs of co-existence in female spotted hyaenas: a life history perspective. Evolutionary Ecology 17: 315-331.

IuCN. 2009. The IUCN Red List of Threatened Species. Available on line at: http://www.iucnredlist.org [Accessed: 06/VII/ 2009].

JaCK, K.M.; B.B. LenZ; E. Healan; S. Rudman; V.A.M. Schoof \& L. Fedigan. 2008. The effects of observer presence on the behavior of Cebus capucinus in Costa Rica. American Journal of Primatology 70 (5): 490-494.

Jorgenson, J.P. \& K.H. Redford. 1993. Human and big cats as predators in the Neotropics, p. 367-390. In: N. Dunstone \& M.L. Gorman (Eds). Mammals as Predators. Oxford, Oxford University Press, 512p.

Kays, R.W. \& J.L. Gittleman. 2001. The social organization of the kinkajou Potos flavus (Procyonidae). Journal of Zoology
253 (4): 491-504.

Kierulff, M.C.M.; B.E. Raboy; P.P. Oliveira; K. Miller; F.C. Passos \& F. Prado. 2002. Behavioral ecology of Lion Tamarins, p.157-187. In: D.G. Kleiman \& A.B. Rylands (Eds). Lion Tamarins, Biology and Conservation. Washington, Smithsonian Institution Press, 422p.

KNIGHT, J. 2001. If they could talk to the animals. Nature 414: 246-247.

Kolowski, J.M.; D. Katan; K.R. Theis \& K.E. HolekamP. 2007. Daily patterns of activity in the spotted hyena. Journal of Mammalogy 88 (4): 1017-1028.

Kunn, T.S. 1970. The Structure of Scientific Revolutions. Chicago, University of Chicago Press, 206p.

MacDonald, D.W. \& O. Courtney. 1996. Enduring social relationships in a population of crab-eating zorro, Cerdocyon thous, in Amazonian Brazil. Journal of Zoology 239: 329-355.

MacNulty, D.R.; L.D. Mech \& D.W. Smith. 2007. A proposed ethogram of large-carnivore predatory behavior, exemplified by the wolf. Journal of Mammalogy 88 (3): 595-605.

Maffei, L.; E. Cuéllar \& A. Noss. 2004. One thousand jaguars (Panthera onca) in Bolivia's Chaco? Camera trapping in the Kaa-lya National Park. Journal of Zoology 262 (3): 295304.

Maffei, L.; R. Paredes, A. Segundo \& A. Noss. 2007. Home range and activity of two sympatric fox species in the Bolivian Dry Chaco. Canid News 10 (4): 1-7.

Mills, G.L. 1992. A comparison of methods used to study food habits of large African carnivores, p. 1112-1124. In: D.R. McCullough \& R.H. Barrett (Eds). Wildlife 2001: populations. Amsterdam, Elsevier, $1164 \mathrm{p}$.

Mittermeier, R.A.; G.A.B. Fonseca; A.B. Rylands \& K. Brandon. 2005. Uma breve história da conservação da biodiversidade no Brasil. Megadiversidade 1 (1): 14-21.

Montgomery, G.G. \& Y.D. Lubin. 1978. Social structure and food habits of crab-eating fox (Cerdocyon thous) in venezuelan llanos. Acta Cientifica Venezelana 29 (1): 382-383.

Murphy, W.J.; E. EIZerik; W.E. Johnson; X.P. Zhang; O.A. Ryder \& S.J. O'Brien. 2001. Molecular phylogenetics and the origins of placental mammals. Nature 409 (6820): 614-618.

Nietzsche, F. 1887. On the genealogy of morals. Arlington, Richer Resources Publications, 136p, [translated by I. Johnston, 2009 new edition].

Oliveira, T.G. 2006. Research on Brazilian terrestrial Carnivora: current knowledge and priorities for the new millennium, p. 39-45. In: R. Morato; F.H.G. Rodrigues; E. Eizirik; P.R. Mangini; F.C.C. Azevedo \& J. Marinho-Filho (Eds). Manejo e conservação de carnívoros neotropicais. São Paulo, Ibama, 396p.

Parmigiani, S. \& F.S. Vom SaAl. 1994. Infanticide and parental care. Chur, Harwood Academic Publishers, 496p.

Pierce, B.M.; V.C. Bleich \& R.T. Bowyer. 2000. Selection of mule deer by mountain lions and coyotes: effects of hunting style, body size, and reproductive status. Journal of Mammalogy 81 (2): 462-472. 
Plavcan, J.M. \& C.B. Ruff. 2008. Canine Size, Shape, and Bending Strength in Primates and Carnivores. American Journal of Physical Anthropology 136 (1): 65-84.

Rosas, C.W.; G.E. Mattos \& M.M.M. Cabral. 2007. The use of hydroelectric lakes by giant otters Pteronura brasiliensis: Balbina Lake in central Amazonia, Brazil. Oryx 41 (4): 520-524.

Rose, L.R.; Perry, S.; Panger, M.A.; J. Katharine; J.H. Manson; J. Gros-Louis; K.C. Mackinnon \& E. Vogel. 2003. Interspecific interactions between Cebus capucinus and other species: data from three Costa Rican sites. International Journal of Primatology 24 (4): 759-796.

Russell A.F.; P.N.M. Brotherton; G.M. McIlrath; L.L. Sharpe \& T.H. Clutton-Brock. 2003. Breeding success in cooperative meerkats: effects of helper number and maternal state. Behavioural Ecology 14: 486-492.

Rylands, A.B.; R.A. Mittermeier \& E. Rodríguez-Luna. 1997. Conservation of Neotropical Primates: threatened species and an analysis of primate diversity by country and region. Folia Primatologica 68 (3-5): 134-160.

Scheibe, K.M.; K. Eichhorn; M. Wiesmayr; B. Schonert \& O. Krone. 2008. Long-term automatic video recording as a tool for analyzing the time patterns of utilization of predefined locations by wild animals. European Journal of Wildlife Research 54 (1): 53-59.

Schleidt, W.M. \& M.D. Shalter. 2003. Co-evolution of human and canids, an alternative view of dog domestication: Homo homini lupus? Evolution and cognition 9 (1): 57-72.

Sechrest, W.; T.M. Brooks; G.A.B. Fonseca; W.R. Konstant; R.A. Mittermeier; A. Purvis; A.B. Rylands \& J.L. Gittleman. 2002. Hotspots and the conservation of evolutionary history. Proceedings of the National Academy of Sciences 99 (4): 2067-2071.

SHIVIK, J.A. 2006. Tools for the edge: what's new for conserving carnivores. BioScience 56 (3): 253-259.

SimÕes-LoPes, P.C. 2005. O luar do delfim, a maravilhosa aventura da História Natural. Florianópolis, Editora Letra D'água, 304p.
Simpson, G.G. 1980. Splendid isolation: the curious history of South American mammals. New Haven, Yale University Press, 266p.

Smith, J.E.; J.M. Kolowski; K.E. Graham; S.E. Dawes \& K.E. HoleKamp. 2008. Social and ecological determinants of fission-fusion dynamics in the spotted hyaena. Animal Behaviour 76 (3): 619-635.

Treves, A. 1999. Has predation shaped the social systems of arboreal primates? International Journal of Primatology 20 (1): 35-67.

Treves, A. \& K.U. Karanth. 2003. Human-carnivore conflict and perspectives on carnivore management worldwide. Conservation Biology 17 (6): 1491-1499.

Treves, A. \& P. Palmevist. 2007. Reconstructing hominin interactions with mammalian carnivores $(6.0-1.8 \mathrm{Ma})$, p. 355-382. In: K.A.I. NeKaris \& S.L. GurSky (Eds). Primate antipredator strategies. New York, Springer, 369p.

Wallace, R.B.; R.L.E. Painter \& A. Saldiania. 2002. An observation of bush dog (Speothos venaticus) hunting behaviour. Mammalia 66: 309-311.

Waser, P.M.; B. Keane; S.R. Creel; L.F. Elliott \& D.J. Minchell. 1994. Possible male coalitions in a solitary mongoose. Animal Behaviour 47 (2): 289-294.

Williamson, E.A. \& A.T.C. Feistner. 2003. Habituating primates: processes, techniques, variables and ethics, p. 25-39. In: J.M. SETChell \& D.J. CurTis (Eds). Field and laboratory methods in Primatology: a practical guide. Cambridge, Cambridge University Press, 370p.

Woodford, M.H.; T.M. Butynski \& W.B. KARESH. 2002. Habituating the great apes: the disease risks. Oryx 36 (2): 153-160.

Wrangham, R.W.; J.L. Gittleman \& C.A. Chapman. 1993. Constraints on group size in primates and carnivores: population density and day-range as assays of exploitation competition. Behavioral Ecology and Sociobiology 32 (3): 199-209.

ZuBERBÜHLER, K. \& D. JeNNy. 2002. Leopard predation and primate evolution. Journal of Human Evolution 43 (6): 873-886.

\title{
Lucas M. Aguiar 1, 2 \& Rodrigo F. Moro-Rios ${ }^{1}$
}

\author{
1 Programa de Pós-graduação em Zoologia, Departamento de Zoologia, Universidade Federal do Paraná. Caixa Postal \\ 19020, 81531-980 Curitiba, Paraná, Brasil. \\ 2 Corresponding author. E-mail: Imaguiar@gmail.com
}

Submitted: 13.III.2009; Accepted: 08.XII.2009.

Editorial responsibility: Luciano M. Verdade 